\title{
Market Garden: A Simulation Environment for Research and User Experience in Smart Grids
}

\author{
Bart Liefers $^{1}$, Felix N. Claessen ${ }^{1}$, Eric Pauwels ${ }^{1}$, \\ Peter A.N. Bosman ${ }^{1}$, and Han La Poutré ${ }^{1,2}$ \\ 1 Centrum Wiskunde \& Informatica (CWI) \\ P.O. Box 94079, 1090 GB Amsterdam, The Netherlands \\ 2 TUDelft, Delft, The Netherlands \\ \{liefers, claessen, pauwels, bosman,hlp\}@cwi.nl
}

\begin{abstract}
Market Garden is a scalable research environment and demonstration tool, in which market mechanisms for smart energy systems and the interaction between end users, traders, system operators, and markets can be simulated. Users can create scenarios in a userfriendly editor in which a hierarchical market architecture and a model of the physical grid can be defined. Individual market mechanisms are set up in a modular fashion, which means they can easily be coupled and interchanged. A visualiser in which the results can be explored in a graphical and intuitive way is included, making Market Garden very suitable for user experience and demonstration purposes.
\end{abstract}

Keywords: Electricity markets, simulation, user experience.

\section{Introduction}

In electrical power systems, a transition towards a more dynamic, decentralized, and interactive structure takes place. In recent decades, electricity wholesale markets were introduced that facilitate competition among a limited number of large energy suppliers. However, trading energy in the competitive environment of the wholesale market subject to the physical constraints of the transmission network is complex. This has inspired many researchers to develop simulation tools (e.g. AMES[1], EMCAS[2], MASCEM[3]), in order to study market design, bidding strategies, ahead planning, and balancing at the transmission level.

However, due to their focus on wholesale power, these simulation tools lack the link to the retail markets, the end users (producing or consuming energy), and the distribution grid. This link is crucial, because many other innovations occur in and around the distribution grid, like smart houses and electric vehicles. Furthermore, distributed generation (wind, solar, micro-CHP) makes up an increasingly large part of our energy supply. These developments give rise to new challenges and opportunities for techniques that enable the exploitation of the available resources more efficiently. PowerMatcher 4 for example focusses on matching supply and demand by letting end users react to dynamic energy

Y. Demazeau et al. (Eds.): PAAMS 2014, LNAI 8473, pp. 351-354, 2014.

(C) Springer International Publishing Switzerland 2014 
prices. However, this system relies solely on real-time balancing. Ahead planning is important for e.g. generators that face startup time, or electric vehicles that need to be fully charged in time.

Regarding the simulation of smart energy systems, Power TAC [5] is a simulation environment in which the retail market is open to energy trading agents in a competitive setting. It includes a wholesale market and customer models, while the trading agents are created by competing researchers. This ensures the traders are competitive, but the market design in which they act is fixed. This can become restrictive, since it is not yet clear what mechanisms will be needed in the future, and different scenarios may require different mechanisms.

In this paper we present Market Garden[1, a simulation environment for research and user experience in smart grids. Like Power TAC, Market Garden focusses on the link between end users and wholesale trading, and the possibility to test trading strategies in a competitive environment. Important distinctive features of Market Garden are the following. The market mechanisms in Market Garden are modular: A library of basic market mechanisms is included, and developers can easily develop and add new mechanisms. The included mechanisms are flexible, allowing trade on arbitrary time scales rather than within fixed timeslots. The simulation of traded energy is combined and directly related with a model of the physical grid, which allows us to include transmission losses and ancillary services. Furthermore, simulations in Market Garden can be run in a hierarchical and distributed computation environment, ensuring scalability to larger simulations, and allowing it to include possibly millions of nodes.

\section{Main Purpose}

Market Garden aims to give experience to end users, traders, or e.g. Distribution System Operators (DSOs) in a smart grid environment. Market results, energy prosumption, network flows, and market organisation can all be visualised in an intuitive way. This makes Market Garden excellently suitable for demonstrations.

With Market Garden, we wish to study market design and timing. The time between trading and delivery of electricity can significantly influence the behaviour of traders in a specific market. This is because for most devices the accuracy of predicted energy output increases as we get closer to real time, and traders may face startup costs or opportunity costs. The market mechanisms in Market Garden have parametrizable time schedules (see below for more details), and thus enable the type of timing-based research that we wish to do.

Another concept of interest is the interaction between end users and retail traders. Most end users are too insignificant to influence market prices, and therefore only react to them. However, the prices form based on the equilibrium between supply and demand. So, from the point of view of a market designer the prices are a consequence of the behaviour of the trading parties, while from

${ }^{1}$ In [6] an informal introduction for a broad audience to an early version of Market Garden was given. 

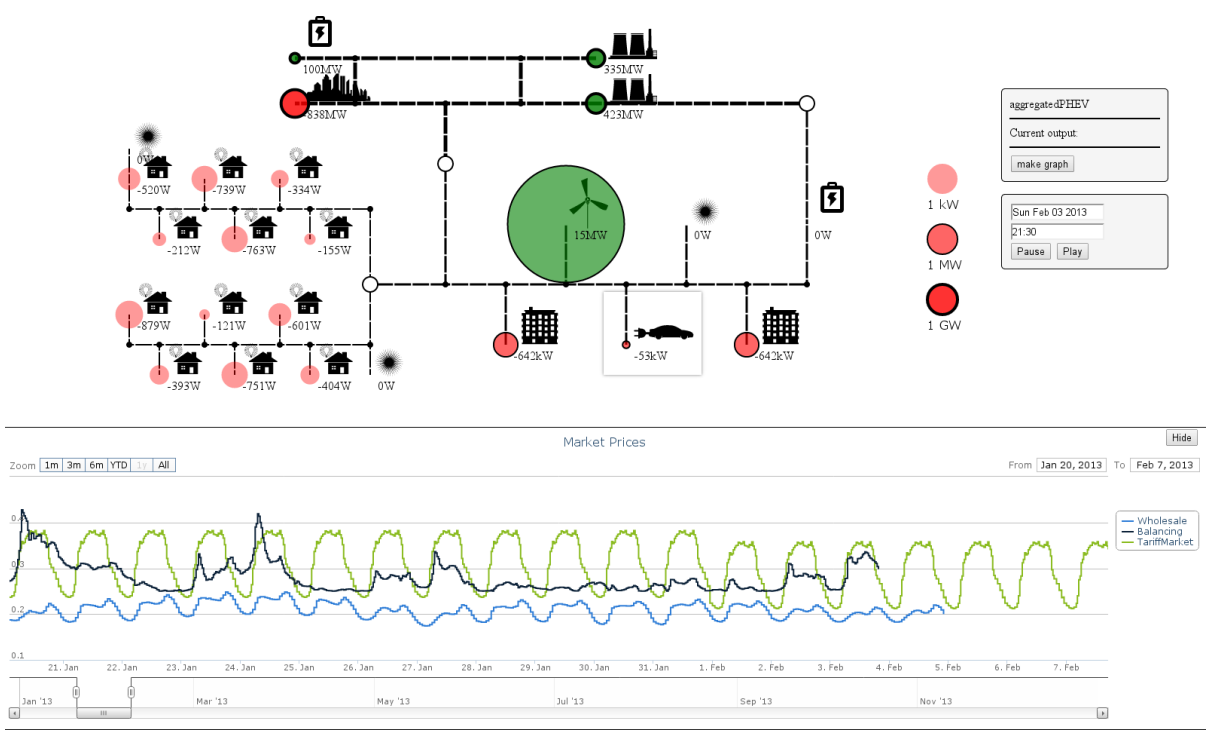

Fig. 1. A screenshot of a part of the visualisation. The green and red circles in the network represent, respectively, energy production and consumption at nodes. The panels at the right provide more detailed information and options. The chart at the bottom depicts the fluctuation of market prices. The green, blue and black lines respectively represent the unit prices of a time-of-use tariff, wholesale, and balancing power.

the point of view of an energy end user the prices define their behaviour. With Market Garden we wish to study this interaction more closely.

\section{Demonstration}

At the heart of Market Garden is the DSO. The DSO monitors the energy supply and demand throughout the network. The network may contain several points of flexibility (ancillary services such as spinning reserves or batteries). The DSO in Market Garden will issue them according to the current needs of the network, such that the total energy loss due to transmission and distribution is minimized.

Nodes in the network represent sets of energy producing or consuming entities. Energy end users can therefore be represented by nodes. For any given time interval in the past, a node can be asked for its energy prosumption. The DSO can aggregate these values to a supply or demand at a substation. This aggregated value can be used as input for a node, representing a subnetwork, in another simulation that runs simultaneously, but possibly on a different machine. Extensive hierarchies can thus be built, yielding a scalable system.

Within a simulation, multiple wholesale markets (e.g. real-time, intra-day) can be defined, on which futures (binding commitments for energy in future timeslots) can be traded. The markets have parametrizable time schedules, so market open and close horizons, timeslot durations, and repetition intervals can 
be specified by the user. Retailers interact with end users by offering tariffs that define the energy prices to which the end users can subscribe. Time-of-use tariffs can be defined, where prices vary on arbitrary time scales (e.g. hourly, weekly or monthly). The retailer is responsible for balancing the energy prosumption of its customers, and can trade on the wholesale markets to achieve this. Imbalances that may occur in real time are resolved by the DSO. The costs for this will be assigned to the retailers through the balancing market present in the simulation.

To ease working with Market Garden, user friendly interfaces are included. Network descriptions and market timing can be defined in an editor. A visualiser can be connected to a running simulation, or it can be started from a log of a previously run simulation. For demonstration purposes, the power flow in the network can be animated and the market organisation can be visualised. The user can create charts of energy prosumption, market prices or network flow in an intuitive and interactive way. A screenshot can be seen in Fig 1 .

\section{Conclusion}

We presented Market Garden, a software environment that can provide valuable insights in energy trading in smart energy systems, and can serve as a unique, scalable research environment in this area. With Market Garden, novel market mechanisms can be tested and validated in an interactive and competitive setting, making it excellently suitable for both research and demonstration purposes. Substantial scalability is achieved, because Market Garden can run in a distributed computation setting. Finally, Market Garden includes a user-friendly visualisation. This can help scientists understand which mechanism works best in a given setting, and policy makers in designing laws and regulations that ensure societal benefits.

Acknowledgements. This project was supported by ICT Labs, as part of the European Institute of Innovation \& Technology (EIT).

\section{References}

1. Li, H., Tesfatsion, L.: Development of Open Source Software for Power Market Research: The AMES Test Bed. Journal of Energy Markets 2(2), 111-128 (2009)

2. Koritarov, V.: Real-world Market Representation with Agents. IEEE Power and Energy Magazine 2(4), 39-46 (2004)

3. Praca, I., Ramos, C., Vale, Z., Cordeiro, M.: MASCEM: A Multiagent System that Simulates Competitive Electricity Markets. IEEE Intelligent Systems 18(6), 54-60 (2003)

4. Kok, J.K., Warmer, C.J., Kamphuis, I.G.: PowerMatcher: Multiagent Control in the Electricity Infrastructure. In: AAMAS 2005: Proceedings of the 4th Int. Joint Conf. on Autonomous Agents and Multiagent Systems, pp. 75-82 (2005)

5. Ketter, W., Collins, J., Reddy, P.: Power TAC: A Competitive Economic Simulation of the Smart Grid. Energy Economics 39, 262-270 (2013)

6. Claessen, F.N., Höning, N., Liefers, B., La Poutré, H., Bosman, P.A.N.: Market Garden: A Scalable Research Environment for Heterogeneous Electricity Markets. ERCIM News 92, 25-26 (2013) 